\title{
Epigenetic silencing of miR-126 contributes to tumor invasion and angiogenesis in colorectal cancer
}

\author{
YU ZHANG $^{1,2^{*}}$, XINYING WANG $^{1 *}$, BINGHONG XU $^{1}$, BAOCAI WANG $^{1}$, ZHONGQIU WANG $^{1}$, \\ YAN LIANG $^{1}$, JIEQIONG ZHOU ${ }^{1}$, JINGJING HU ${ }^{1}$ and BO JIANG ${ }^{1}$ \\ ${ }^{1}$ Guangdong Provincial Key Laboratory of Gastroenterology, Department of Gastroenterology, Nangfang Hospital, \\ Southern Medical University, Guangzhou, Guangdong 510515; ${ }^{2}$ Department of Gastroenterology, \\ The First People's Hospital of Yunnan Province, Kunming, Yunnan 650032, P.R. China
}

Received June 7, 2013; Accepted July 5, 2013

DOI: $10.3892 /$ or.2013.2633

\begin{abstract}
RNAs (miRNAs) have been reported to play a crucial role in regulating a variety of genes pivotal for tumor metastasis. miR-126 is well known as one of the angiogenesis regulatory miRNAs. Recent studies have reported controversial roles of miR-126 in tumor progression. In this study, we sought to investigate the potential roles of miR-126 in colorectal cancer (CRC). By real-time PCR, miR-126 was shown to be downregulated in primary CRC tissues and cell lines. Restoration of miR-126 in CRC cells inhibited cell growth, migration and invasion. Using both in silico prediction and immunoblotting, we found that vascular endothelial growth factor (VEGF) was a target of miR-126. The interaction of miR-126 on the 3'UTR of VEGF mRNA was validated by luciferase reporter assay. Mechanistically, we found that the silencing of miR-126 was induced by promoter methylation of its host gene, EGFL7. Treatment with 5-aza-CdR restored miR-126 expression and thereby led to a decline in VEGF expression. Functionally, due to suppression of VEGF, enhanced miR-126 expression inhibited tumor neovasculature triggered by CRC cells. In conclusion, our findings suggest that DNA methylation-induced silencing of miR-126 contributes, at least in part, to tumor invasion and angiogenesis in CRC, through upregulation of VEGF expression. miR-126 may be a potential target for the therapeutic strategy against CRC.
\end{abstract}

Correspondence to: Professor Bo Jiang, Guangdong Provincial Key Laboratory of Gastroenterology, Department of Gastroenterology, Nangfang Hospital, Southern Medical University, 1838 North Guangzhou Road, Guangzhou, Guangdong 510515, P.R. China E-mail: drjiang@163.com

*Contributed equally

Abbreviations: VEGF, vascular endothelial growth factor; UTR, untranslated region; miRNA, microRNA; ELISA, enzyme-linked immunosorbent assay

Key words: miR-126, invasion, tumor angiogenesis, colorectal cancer, methylation

\section{Introduction}

Colorectal cancer (CRC) is the third most common cancer and the leading cause of cancer-related mortality worldwide (1), with a high potential for tumor invasion and metastasis. Similar to many other solid malignancies, metastasis of CRC involves proteolysis of the extracellular matrix, alterations in tumor cell adhesion and motility, and colonization in distant organs (2). In addition, formation of new blood vessels is also indispensable for the persistence of metastastic growth. Despite the obvious importance of metastasis, the molecular mechanism underlying these processes remains unclear.

Growing evidence has recently supported the cancerrelated effects of microRNAs (miRNAs), a newly identified class of small non-coding RNA molecules which function through negatively regulating target gene expression. They can bind to specific complementary sites within the $3^{\prime}$ untranslated regions (3'UTRs) of their target mRNA, to inhibit translation or to induce degradation, even to regulate mRNA transcription (3-5). Recent studies have revealed the critical role of miRNAs in regulating a variety of genes pivotal for invasion or metastasis $(6,7)$.

miR-126, which locates within intron 7 of the epidermal growth factor-like domain 7 gene (EGFL7), is highly expressed in endothelial cells. Two studies have reported its crucial role in promoting embryonic angiogenesis by promoting vascular endothelial growth factor (VEGF) signaling in zebrafish (8) and in a mouse model (9). In contrast, miR-126 was identified to be one of the dysregulated miRNAs in multiple cancer types. Its downregulation was observed in breast, pancreatic and gastric cancer (10-12). Low expression of miR-126 in non-small cell lung cancer and renal cell carcinoma was significantly correlated with reduced patient survival $(13,14)$. Through targeting oncogenic genes, such as SLC7A5, Crk and ADAM9, miR-126 plays a role as a tumor suppressor to inhibit tumor cell proliferation, invasion and the EMT process $(11,15,16)$. Conversely, some recent studies have presented an oncogenic role of miR-126. They found that overexpression of miR-126 may contribute to gastric carcinogenesis by inhibiting SOX2 expression (17), and was highly associated with metastasis of prostate cancer (18). These contradictory results imply that miR-126 may function 
by diverse mechanisms in different physiological and pathological contexts.

VEGF has commonly been acknowledged as the most prominent factor to promote tumor development (19). It operates to increase the permeabilization of blood vessels and induces formation of new blood vessels, to facilitate orthotopic and metastatic growth. In CRC, VEGF signaling involved neovascularity represents a key mediator of tumor initiation and dissemination (20).

Quite recently, studies have shown decreased expression of miR-126 in CRC (21), and that DNA methylation results in the silencing of miR-126 in bladder and lung cancer $(22,23)$. Of specific note, in silico prediction indicates that miR-126 has a conserved binding site within the 3'UTR of VEGF mRNA. We thus hypothesized that overexpression of VEGF in CRC is, at least partly, due to silencing of miR-126 caused by DNA methylation.

\section{Materials and methods}

Tissue samples and cell lines. Twelve pairs of primary CRC and matched adjacent normal colonic epithelium, and 62 primary CRC tissues were collected. All samples were obtained from patients who underwent surgical resection at Nanfang Hospital (Guangzhou, China) and were snap-frozen in liquid nitrogen, and stored at $-80^{\circ} \mathrm{C}$ for further use.

HEK293 cell line and 6 human CRC cell lines, including LoVo, HT29, SW480, SW620, SW1116 and HCT116, were purchased from the American Type Culture Collection (Manassas, VA, USA). The cells were maintained routinely in RPMI-1640 (Gibco-BRL, Carlsbad, CA, USA) supplemented with $10 \%$ fetal bovine serum (Sigma, St. Louis, MO, USA) and cultured at $37^{\circ} \mathrm{C}$ in a $5 \% \mathrm{CO}_{2}$ atmosphere.

TaqMan real-time-PCR analysis of miR-126 expression. TaqMan real-time-PCR was performed to detect mature miR-126 expression in tissue sample and cell lines. Total RNA was extracted using TRIzol reagent (Invitrogen Life Technologies, Carlsbad, CA, USA). Expression of mature miR-126 was determined by the TaqMan miRNA assay (Applied Biosystems, Foster City, CA, USA). Data were processed using the $2^{-\Delta \Delta C t}$ method. RNU6B (Ambion, Austin, TX, USA) was used as an endogenous control.

Ectopic miR-126 expression. Enforced expression of miR-126 in LoVo and SW620 cells was achieved by transfection with pre-miR-126 (Ambion). Cells were seeded in 6-well clusters or 96-well plates for $24 \mathrm{~h}$ and transfected with $30 \mathrm{nM}$ pre-miR126 using Lipofectamine 2000 (Invitrogen Life Technologies) for 24 or $48 \mathrm{~h}$. Scramble precursor (Ambion) was used as a negative control. Transfected LoVo and SW620 cells were used in further functional assays or for RNA/protein extraction.

Cell proliferation assay. Alamar blue assay (Invitrogen Life Technologies) was conducted to measure cell proliferation. Cells were seeded in a 96-well plate at $0.5 \times 10^{4} /$ well for $24 \mathrm{~h}$, then transfected with pre-miR-126 or scramble control. The transfected cells were incubated for 24,48 and $72 \mathrm{~h}$, respectively. Ten microliters of Alamar blue reagent was added to each well at $2 \mathrm{~h}$ before the end of the incubation. Following the incubation, the absorbance of each well at $570 \mathrm{~nm}(600 \mathrm{~nm}$ as reference wavelength) was determined using a microplate reader.

Cell invasion and migration assays. The invasive potential of LoVo and SW620 cells was evaluated using a cell invasion assay kit (Millipore, Billerica, MA, USA) following the manufacturer's instructions. Briefly, transfected cells were resuspended in serum-free RPMI-1640 medium at a density of $1.0 \times 10^{6} / \mathrm{ml}$. Cell suspension (300 $\left.\mu \mathrm{l}\right)$ and $500 \mu \mathrm{l}$ RPMI-1640 containing $10 \%$ FBS were respectively added to each insert and the matched lower chamber. After $48 \mathrm{~h}$, non-invading cells were removed using a cotton swab, and then the underside of the insert was stained. Six random fields (at a magnification of $\mathrm{x} 100$ ) for each insert were counted. For the migration assay, the procedures were similar to those of the invasion assay, except that $200 \mu \mathrm{l}$ cell suspension was cultured in each Transwell upper insert (Corning Incorporated, Corning, NY, USA) for $48 \mathrm{~h}$. For human microvascular endothelial cell (HMVEC) migration, $1.0 \times 10^{5}$ transfected LoVo cells were seeded in the lower chamber and incubated for $24 \mathrm{~h}$. Then $5 \times 10^{4}$ HMVECs were added in the matched upper insert, and co-cultured with LoVo cells for $4 \mathrm{~h}$. The underside of the insert was stained. Six random fields (at a magnification of x100) for each insert were counted.

Western blot analysis. Immunoblotting was performed to detect the expression of VEGF in CRC cell lines after transfection. Protein $(30 \mu \mathrm{g})$ was loaded onto a SDS-PAGE gel, transferred onto a PVDF membrane and subsequently probed with 1:1,000 diluted mouse monoclonal VEGF-A antibody (Cell Applications, San Diego, CA, USA) at $4^{\circ} \mathrm{C}$ overnight, followed by incubation with HRP-conjugated secondary antibody. Signals were visualized using ECL substrates (Millipore). $\beta$-actin was used as an endogenous protein for normalization.

ELISA assay. An ELISA kit (Cusabio, China) was used to detect the VEGF concentration in the cell supernatant following the manufacturer's instructions.

Luciferase reporter assay. The full-length 3'UTR of VEGF (1923 nt) containing one miR-126 potential binding site was amplified by PCR using the following primers: VEGF-A forward, 5'-CCGctcgagGCCGGGCAGGAGGAAGGAG-3' and reverse, 5'ATAAGAATgcggccgcTGAGATCAGAATT AAATTCTTTAATAC-3'. The PCR product was subcloned into a psiCHECK-2 vector (Promega Corporation, Madison, WI, USA) immediately downstream to the luciferase gene sequence. A psiCHECK-2 construct containing 3'UTR of VEGF with a mutant seed sequence of miR-126 was also synthesized using the primers: mutVEGF-A forward, 5'-AAG AGAAAGTGTTTTATATATCGATCTTATTTAATATCCC TTTTTA-3' and reverse, 5'-TAAAAAGGGATATTAAATAA GATCGATATATAAAACACTTTCTCTT-3'.

All constructs were verified by DNA sequencing. HEK293 cells were plated in 24-well clusters, then co-transfected with $500 \mathrm{ng}$ constructs with or without miR-126 precursors. At $48 \mathrm{~h}$ after transfection, luciferase activity was detected using a dual-luciferase reporter assay system (Promega Corporation) and normalized to Renilla activity. 
In vitro and in vivo angiogenesis assays. In vitro and in vivo angiogenesis assays were conducted to determine the potential of miR-126 to affect tumor vascularity. For the in vitro Matrigel tube formation study, HMVECs were seeded in a 96-well plate pre-coated with growth factor-reduced Matrigel (BD Biosciences). Conditioned medium (CM) obtained from miR-126 precursor or scramble control transfected cells was added, followed by incubated at $37^{\circ} \mathrm{C}$ for $12 \mathrm{~h}$. The capacity of tube formation was assessed by counting the tubes in 3 randomly chosen fields under an inverted microscope (at a magnification of $\mathrm{x} 100$ ). The tubes were defined as structures formed by 2 identifiable HMVECs connecting at both ends. In vivo, the chorioallantoic membrane (CAM) model was performed as previously described (24).

5-Aza-2'-deoxycytidine (5-aza-CdR) treatment. For the demethylation study, the $6 \mathrm{CRC}$ cell lines were treated with 5-Aza-CdR (Sigma) at a concentration of $3 \mu \mathrm{M}$ for $72 \mathrm{~h}$, replacing the medium and the drug every $24 \mathrm{~h}$.

DNA methylation analysis. To establish the methylation status of miR-126 CpG islands, we performed 2 types of PCR analysis of bisulfate-modified genomic DNA (Active Motif, Carlsbad, CA, USA). First, the methylation-specific PCR (MSP) of CRC cell lines was conducted using methylated and unmethylated primers: M forward,5'-TTTAAGTTATTTTTTT TAGGTTCGG-3' and reverse, 5'-ATTATATAACCTCCTCCT AAAACGC-3'; U forward, 5'-TTTAAGTTATTTTTTTTA GGTTTGG-3' and reverse, 5'-TTATATAACCTCCTCCTAA AACACC-3'.

PCR products were subjected to $2.5 \%$ agarose gel electrophoresis and visualized by ethidium bromide staining and UV transillumination. Second, bidirectional bisulfite sequencing (BSP) was used to analyze the corresponding $\mathrm{CpG}$ islands. PCR products were subcloned into the $\mathrm{pMD}^{\circledR} 18$-T vector (Takara, China), 3 candidate clones were selected and sequenced. The primers used were as follows: forward, 5'-GTGTGGTTAGG GGTTGTGTT-3' and reverse, 5'-CACACCCAATACTCAAA AAATTTC-3'.

Statistical analysis. All data from 3 independent experiments are expressed as means \pm SD and processed using SPSS 13.0. The expression of miR-126 in CRC tissues and matched adjacent colonic epithelium was compared by paired t-test. The difference between the experimental groups and control was estimated by one-way ANOVA. A P-value of $<0.05$ was considered to indicate a statistically significant result.

\section{Results}

miR-126 is commonly downregulated in CRC. We performed real-time PCR using TaqMan probe to detect the endogenous miR-126 level in primary CRC tissues and cell lines. miR-126 was significantly decreased in all of the 12 CRC tissues when compared to their matched adjacent normal colonic tissues (Fig. 1A). We extended the test to 6 human CRC cell lines: LoVo, SW620, SW480, SW1116, HT29 and HCT116. These 6 cell lines showed notable loss of miR-126, whereas the control normal colonic mucosa pooled from 3 individuals expressed a strong level of miR-126 (Fig. 1B).
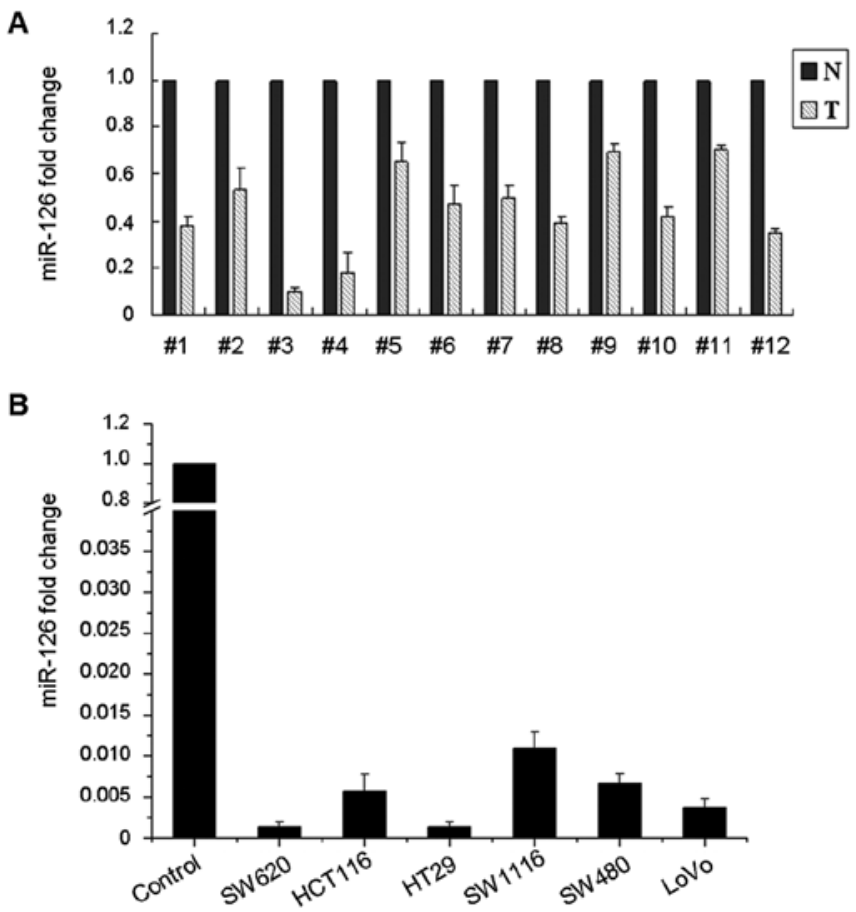

Figure 1. Decreased miR-126 expression in CRC tissues and cell lines. (A) TaqMan real-time PCR results for the fold change of miR-126 in 12 CRC tissues compared to their matched adjacent normal colon epithelium. (B) TaqMan real-time PCR results for the fold change of miR-126 in 6 CRC cell lines relative to the normal colon epithelium pooled from 3 healthy individuals. Results were normalized to RU6B. CRC, colorectal cancer.

miR-126 directly suppresses the expression of VEGF at the post-transcriptional level. Using in silico prediction database, we hypothesized that VEGF is a potential target gene of miR-126 (Fig. 2A). We initially tested the VEGF expression profile in $6 \mathrm{CRC}$ cell lines. All of the cell lines exhibited notable expression of VEGF (Fig. 2B). LoVo and SW620 cells were selected to verify our hypothesis. Both LoVo and SW620 cells were transfected with pre-miR-126 to restore miR-126 expression. Restoration of miR-126 in the cell lines significantly suppressed VEGF protein expression (Fig. 2D). However, no alteration in VEGF mRNA was observed by qPCR (data not shown). This indicates that miR-126 may target VEGF at the translational level.

To further confirm whether the inhibition of VEGF is due to the interaction between miR-126 and the putative binding site in 3'UTR of VEGF mRNA, we constructed a luciferase reporter vector with the putative VEGF 3'UTR binding site for miR-126 and its mutant version by site direct mutagenesis (Fig. 2A). We transfected the luciferase reporter vector alone or together with pre-miR-126 or scramble control into HEK293 cells. A significant decrease in luciferase activity was noted when the VEGF 3'UTR vector was co-transfected with pre-miR-126, compared to the mutant vector, whereas the miR-126-mediated suppression of luciferase activity was abolished in the mutant VEGF 3'UTR vector (Fig. 2C). These results confirm a direct interaction of miR-126 on VEGF 3'UTR.

miR-126 inhibits CRC cell growth, migration and invasion. We performed gain of function assays to validate whether 
A
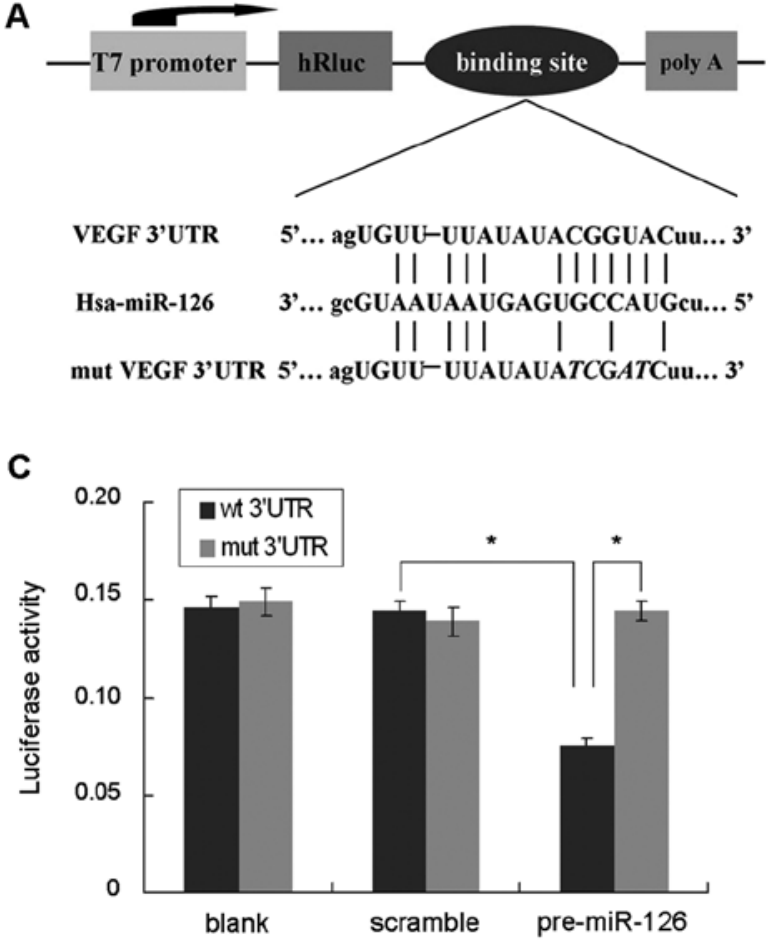

B

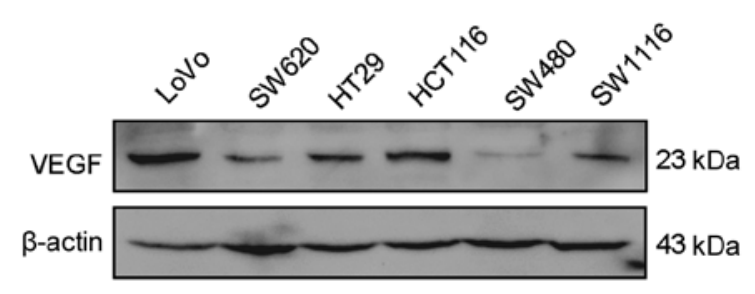

D

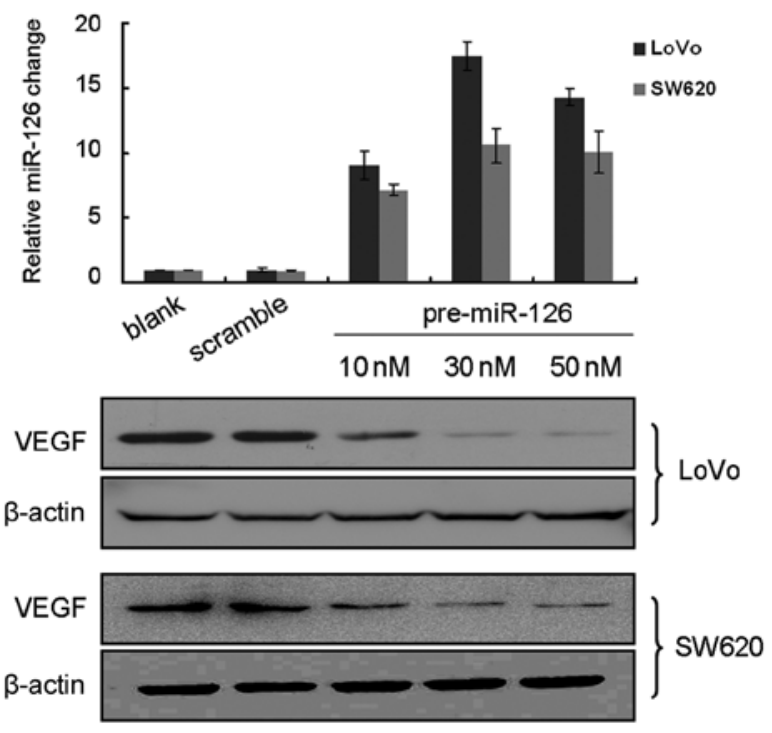

Figure 2. miR-126 suppresses VEGF expression by directly binding to its 3'UTR. (A) The wild-type (wt) VEGF 3'UTR and mutated (mut) VEGF 3'UTR were subcloned into psiCHECK-2 luciferase vector. The predicted miR-126 binding site within VEGF 3'UTR is shown. The mutated binding site is represented in italics. (B) Variable VEGF expression in 6 CRC cell lines as determined by western blotting. $\beta$-actin was used as the loading control. (C) The suppression of luciferase activity by VEGF 3'UTR was dependent on miR-126. Mutated VEGF 3'UTR abrogated miR-126-mediated suppression of luciferase activity ("P<0.05). (D) Restoration of miR-126 by pre-miR-126 transfection significantly suppressed VEGF protein expression in LoVo and SW620 cells. VEGF, vascular endothelial growth factor; 3'UTR, 3' untranslated region; CRC, colorectal cancer.

miR-126 regulates cellular processes, including cell growth, migration and invasion. Restoration of miR-126 in LoVo and SW620 cells significantly inhibited cell growth (Fig. 3A). In the Transwell migration assay, restoration of miR-126 in LoVo cells apparently impaired cell migration and invasion when compared to the blank and scramble control (Fig. 3B). Similar results were also observed in parallel assays using SW620 cells (Fig. 3C).

miR-126 exerts anti-angiogenenic effects on CRC. We investigated whether miR-126 regulates tumor vasculature via mediation of VEGF expression. First, ELISA assay was performed to detect VEGF secretion by CRC cell lines (Fig. 4A) and the concentration of VEGF in conditioned medium (CM) obtained from pre-miR-126-transfected LoVo cells (Fig. 4B). Restoration of miR-126 resulted in decreased VEGF secretion by LoVo cells to the culture medium (Fig. 4B). When human microvascular endothelial cells (HMVECs) were co-cultured with pre-miR-126-transfected LoVo cells in the Transwell system, the migration of HMVECs was significantly inhibited (Fig. 4C). Correspondingly, in the endothelial tube formation assay, we observed the reduced spontaneous ability of HMVECs to form capillary tubes in the presence of CM obtained from pre-miR-126-transfected LoVo cells, when compared with tube formation in the presence of $\mathrm{CM}$ from the blank and scramble controls (Fig. 4D). For further validation of the anti-angiogenic effect of miR-126 in vivo, we performed chick embryo chorioallantoic membrane assay (CAM) using gelatin sponge loaded with the different $\mathrm{CM}$ as mentioned. The neo-vessel formation was significantly inhibited in the presence of CM from the pre-miR-126-transfected LoVo cells (Fig. 4E).

miR-126 is epigenetically silenced in CRC. To validate whether miR-126 is silenced by DNA methylation, we examined the methylation status of EGFL7, the host gene of miR-126, in primary CRC tissues and cell lines. The $\mathrm{CpG}$ island status within the EGFL7 promoter region, along with the localization of PCR products, is presented in Fig. 5A. Clinicopathologic features of CRC patients are listed in Table I. Notably, there was no significant association observed between methylation status and TNM stage. Using methylation-specific PCR (MSP), all of the CRC cell lines showed extensively methylation of the EGFL7 promoter (Fig. 5B). Bisulfate sequencing (BSP) results exhibited extensive methylation throughout the promoter region of these cell lines (Fig. 5C). We treated the same panel of CRC cell lines with 5-aza-CdR. Compared to the untreated cells, enhanced expression of miR-126 and downregulation of VEGF were observed in the demethylated cells (Fig. 5D). These results suggest that promoter methylation resulted in the silencing of miR-126 in CRC, and may be partly responsible for the high VEGF expression in CRC. 
A

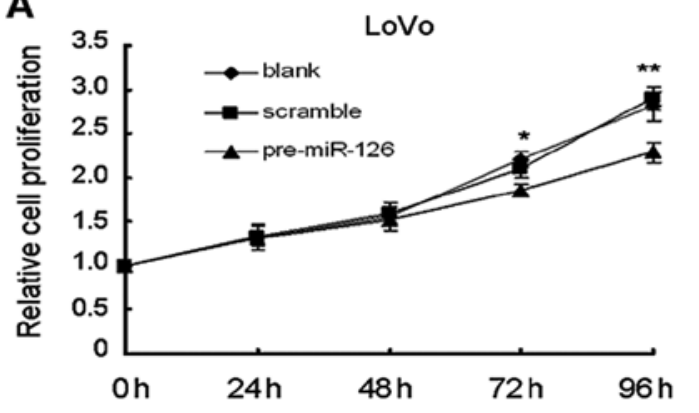

B
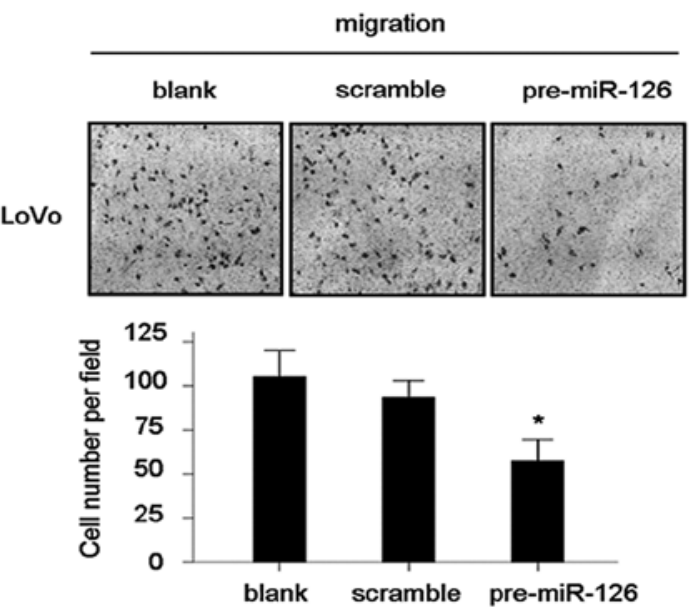

C
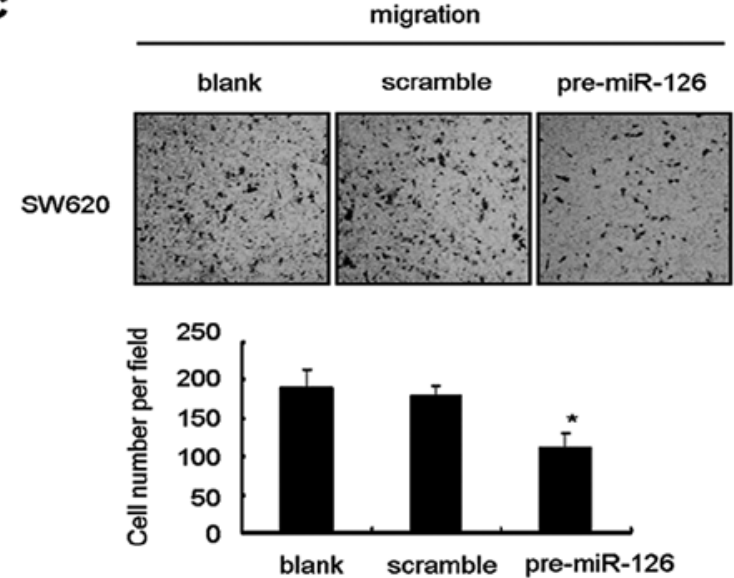

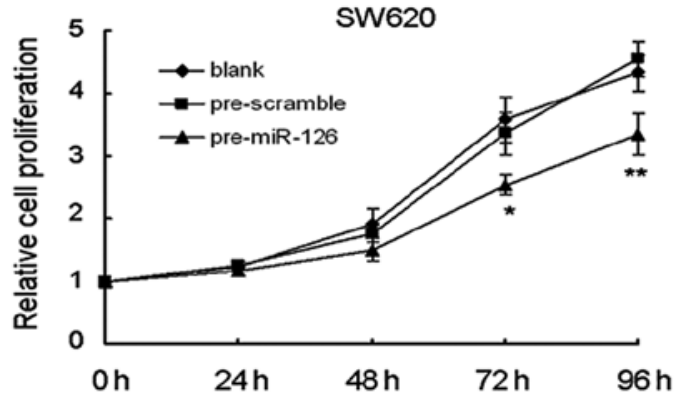

invasion
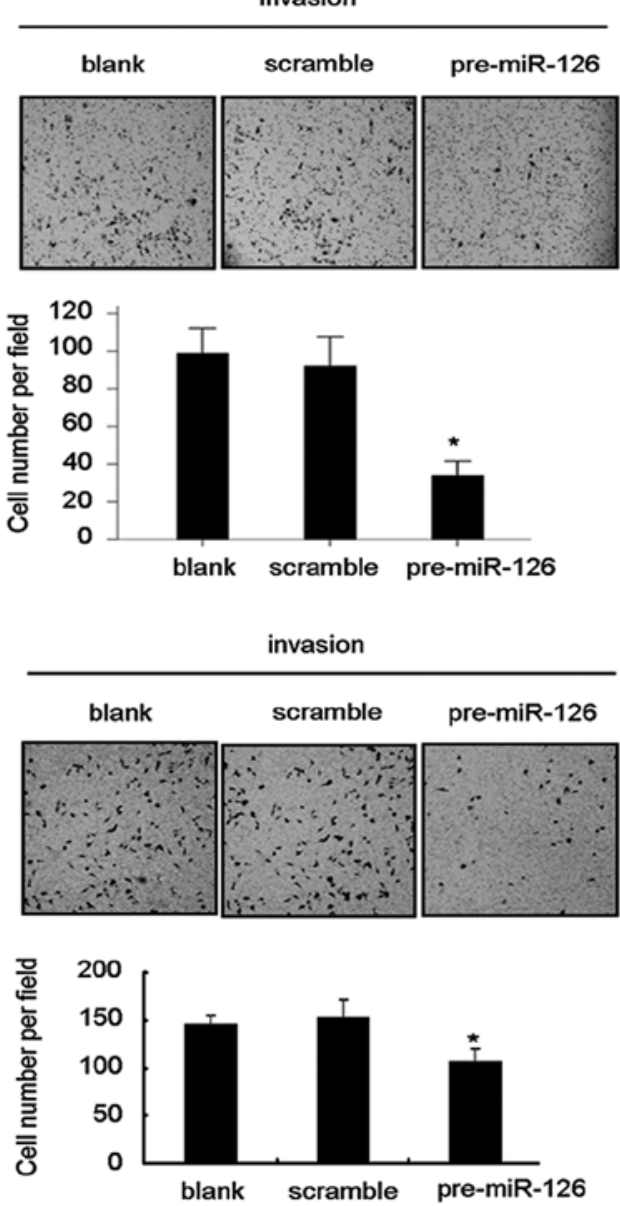

Figure 3. miR-126 suppresses cell growth, migration and invasion of CRC cells. (A) Enhanced expression of miR-126 inhibited cell growth of LoVo and SW620 cells ( $\mathrm{P}<0.05$, compared with controls). (B and C) Transwell assay was performed to measure migration and invasion ability. (B) Reduced migration and invasion ability of LoVo cells at $48 \mathrm{~h}$ post-transfection with pre-miR-126 ( $\mathrm{P}<0.05$, compared with controls). (C) Reduced migration and invasion ability of SW620 cells at $48 \mathrm{~h}$ post-transfection with pre-miR-126 ( ${ }^{*} \mathrm{P}<0.05$, compared with controls). CRC, colorectal cancer.

\section{Discussion}

The majority of deaths from tumors result from complications caused by metastasis. Therefore, targeting metastatic disease is a pivotal anticancer strategy. miRNAs have been implicated in the regulation of cellular processes which are deregulated in tumors, including proliferation, apoptosis, differentiation, cell migration and invasion (25), and even tumor angiogenesis (26). Recent studies have identified various miRNAs that may promote $(27,28)$ or inhibit $(29,30)$ tumor invasion and metastasis, providing potential therapeutic targets for anti-metastatic strategy. miR-126 is well known as one of the angiogenesis regulatory miRNAs that are termed angiomiRs (31). Emerging evidence indicates that miR-126 plays a regulatory role in tumor progression. Tavazoie et al (10) reported that miR-126 inhibits overall tumor growth and proliferation, and suppresses metastatic colonization and angiogenesis by blocking endothelial recruitment in breast cancer (32). In pancreatic cancer, restoration of miR-126 results in reduced cellular migration, invasion, and induction of the epithelial marker E-cadherin via suppression of ADAM9 (11). Enhanced expression of miR-126 was also reported to increase the sensitivity of lung cancer cells to anticancer agents (33). Based on these findings, we hypothesized that miR-126 may be involved in CRC metastatic processes. The most significant finding of our study was that restoration of miR-126 directly suppressed VEGF expression 
A

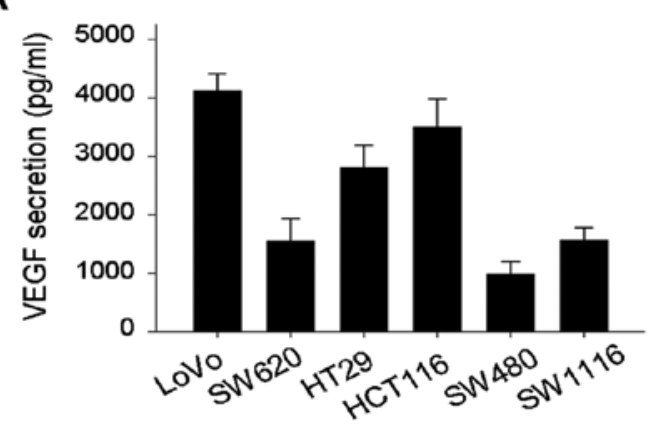

C
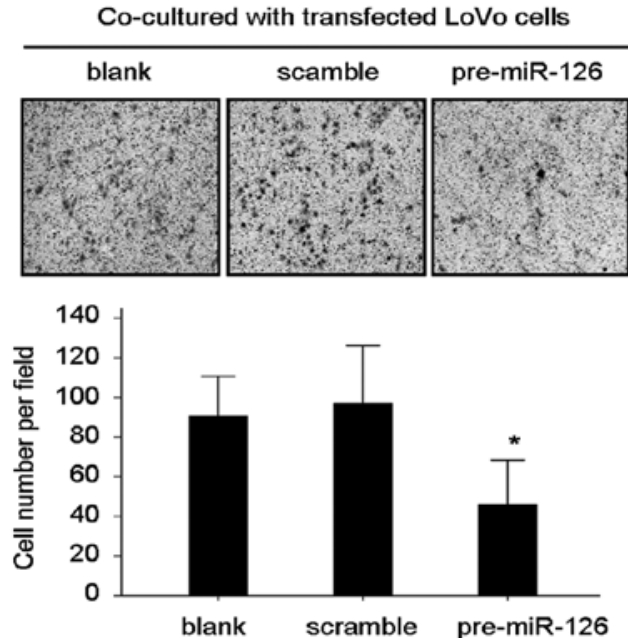

$\mathbf{E}$

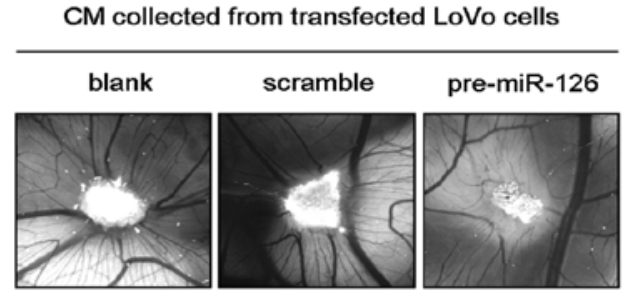

B

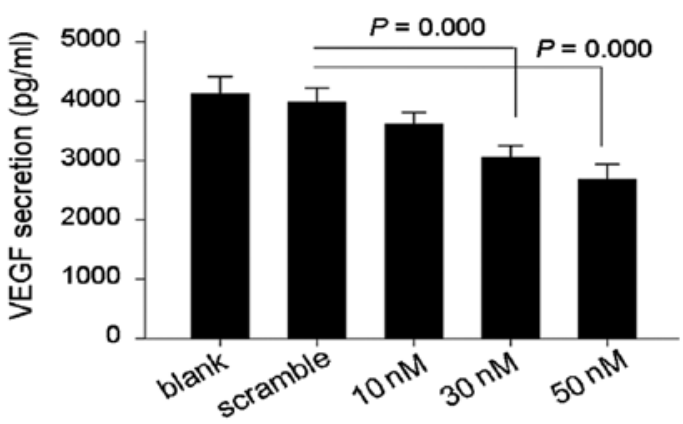

CM collected from transfected LoVo cells
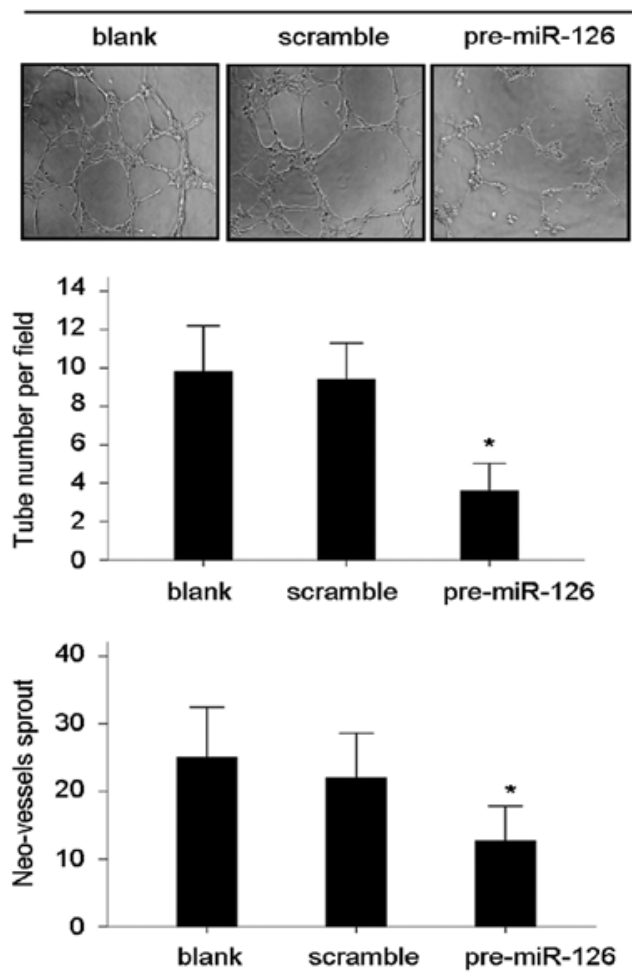

Figure 4. miR-126 inhibits CRC tumor angiogenesis. (A) Concentration of VEGF in CM obtained from 6 CRC cell lines was determined by ELISA. (B) Concentration of VEGF in CM obtained from pre-miR-126 or scramble transfected LoVo cells was determined by ELISA. Restoration of miR-126 suppressed VEGF secretion of LoVo cells. (C) HMVECs were co-cultured with LoVo cells in the Transwell system. The migratory ability of HMVECs was decreased in response to restoration of miR-126 in LoVo cells cultured in the lower chamber ( $\mathrm{P}<0.05$, compared with controls). (D) HMVECs were seeded on the top of ECM-matrix, in the presence of the CM as previously mentioned. The ability of HMVECs to form capillary tubes was inhibited, in response to restoration of miR-126 ( $\mathrm{P}<0.05$, compared with controls). (E) Angiogenic response induced by gelatin sponges loaded with CM was assessed using in vivo chick embryo chorioallantoic membrane (CAM) assay. Neo-vessels sprouted at the sponge-CAM boundary were counted under a stereomicroscope. Restoration of miR-126 impeded neo-vessel formation ("P<0.05, compared with controls). CRC, colorectal cancer; VEGF, vascular endothelial growth factor; CM, conditioned medium; HMVECs, human microvascular endothelial cells.

consequently inhibiting cell invasion and tumor angiogenesis in CRC. In addition, DNA methylation was responsible, at least in part, for the silencing of miR-126 expression in CRC.

Our results showed that miR-126 was commonly downregulated in $6 \mathrm{CRC}$ cell lines and the $12 \mathrm{CRC}$ patient tissues, which is consistent with a previous study (21). On the contrary, Otsubo et al (17) reported miR-126 was highly expressed in cultured and primary gastric cancer cells. This implies that the regulatory role of miR-126 may be specific to tumor context. Using a luciferase reporter, we revealed that miR-126 directly binds to a specific complementary site within the $3^{\prime}$ untranslated region of VEGF mRNA. In the gain of function assays, we restored miR-126 expression in metastatic LoVo cells and found that re-expression of miR-126 suppressed VEGF expression post-transcriptionally. Moreover, restoration of miR-126 impaired cell growth, migration and invasion capability. It is essential for VEGF to regulate tumor progression through interaction with its tyrosine kinase receptors (VEGFRs) (34). Particularly, activation of VEGF/VEGFR1 signaling was found to lead to significant induction of cell motility and invasiveness of CRC cells (35). Therefore, our data indicated that miR-126 inhibited cell migration and invasion through inhibition of VEGF expression. Since tumor cell-released VEGF contributes to tumor vasculature via stimulation of the sprouting and proliferation of endothelial cells (26), we investigated the involvement of miR-126 in tumor angiogenesis of 
A

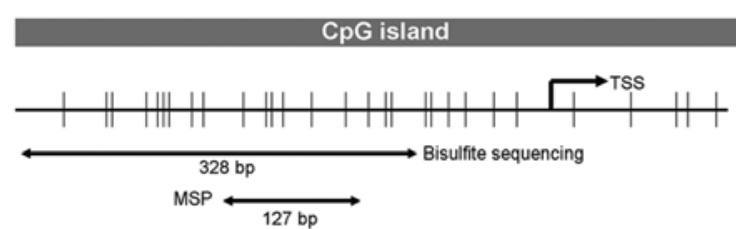

B

\begin{tabular}{|c|c|c|c|c|c|c|c|c|c|c|c|c|c|}
\hline \multicolumn{2}{|c|}{ LoVo } & \multicolumn{2}{|c|}{ SW620 } & \multicolumn{2}{|c|}{ HT29 } & \multicolumn{2}{|c|}{ НСТ116 } & \multicolumn{2}{|c|}{ SW480 } & \multicolumn{2}{|c|}{ SW1116 } & \multicolumn{2}{|c|}{$\mathrm{H}_{2} \mathrm{O}$} \\
\hline$M$ & $u$ & $M$ & $U$ & $M$ & $u$ & N & $u$ & M & $u$ & n & $u$ & & $u$ \\
\hline 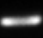 & & & - & $=$ & & $=$ & $\rightarrow$ & $=$ & & - & - & & \\
\hline
\end{tabular}

C

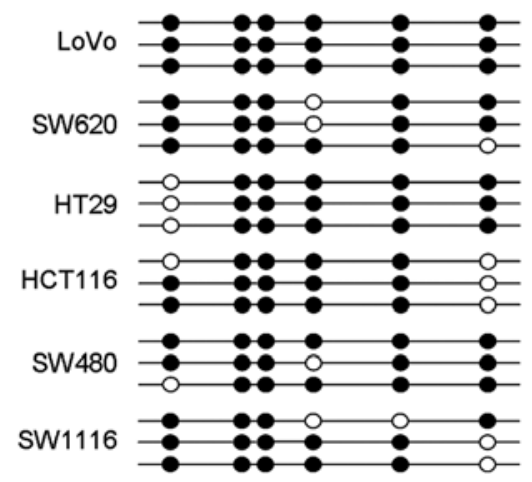

D

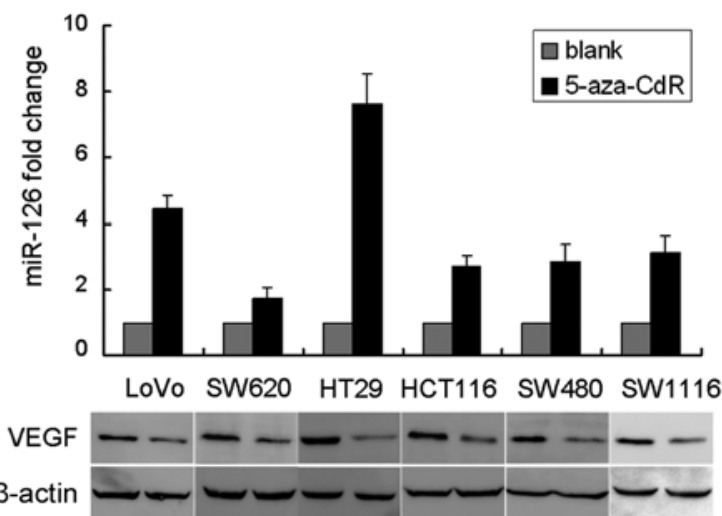

Figure 5. Analysis of the methylation status of miR-126 CpG islands. (A) miR-126 is an intronic miRNA located within intron 7 of the EGFL7 gene. Top, location of miR-126 within the EGFL7 gene. Bottom, map of the EGFL7 CpG island within the promoter region, with the positions of PCR products used for methylation analysis. Vertical tick marks, CpG sites; E, exon; TSS, putative transcribe start site. (B) Methylation status of the EGFL7 promoter region in 6 CRC cell lines by MSP. M, methylated; U, unmethylated. (C) Bisulfate sequencing of CpG islands within the EGFL7 promoter region in $6 \mathrm{CRC}$ cell lines. Each circle indicates a CpG dinucleotide. Black circle, methylated CpG; open circle, unmethylated CpG. Three clones were sequenced for each cell line. (D) miR-126 fold change was determined by TaqMan real-time PCR and VEGF expression was determined by western blotting in 6 CRC cell lines following 5-aza-CdR treatment. miRNA, microRNA; EGFL7, epidermal growth factor-like domain 7; CRC, colorectal cancer; MSP, methylation-specific PCR; VEGF, vascular endothelial growth factor; 5-aza-CdR, 5-aza-2'-deoxycytidine.

Table I. Clinicopathological features of the CRC patients analyzed for miR-126 methylation.

\begin{tabular}{lcccc}
\hline Characteristics & $\begin{array}{c}\text { miR-126 methylated } \\
\mathrm{n}=52\end{array}$ & $\begin{array}{c}\text { miR-126 unmethylated } \\
\mathrm{n}=10\end{array}$ & $\begin{array}{c}\text { Total } \\
\mathrm{n}=62\end{array}$ & P-value \\
\hline Age (years), mean $\pm \mathrm{SD}$ & $57.83 \pm 13.76$ & $57.1 \pm 11.61$ & $57.71 \pm 13.35$ & $0.156^{\mathrm{a}}$ \\
Age, $\geq 60$ years & $25(48.1)$ & $4(40)$ & $29(46.8)$ & $0.902^{\mathrm{b}}$ \\
Female, $\mathrm{n}(\%)$ & $27(51.9)$ & $5(50)$ & $32(51.6)$ & $0.911^{\mathrm{b}}$ \\
Proximal site, $\mathrm{n}(\%)$ & $8(15.4)$ & $2(20)$ & $10(16.1)$ & $1^{\mathrm{b}}$ \\
Poorly differentiation, $\mathrm{n}(\%)$ & $8(15.4)$ & $1(10)$ & $9(14.5)$ & $1^{\mathrm{b}}$ \\
Mucinous adenocarcinoma, n (\%) & $3(5.8)$ & $2(20)$ & $5(8.1)$ & $0.379^{\mathrm{b}}$ \\
TNM, n (\%) & & & & $0.348^{\mathrm{b}}$ \\
I & $9(17.3)$ & $4(40)$ & $13(21.0)$ & \\
II & $15(28.8)$ & $2(20)$ & $27(43.5)$ & $5(8.1)$ \\
III & $23(44.2)$ & $4(40)$ & $0(0)$ & \\
IV & $5(9.6)$ & & \\
\hline
\end{tabular}

${ }^{a}$ Evaluated by Student's t-test; bevaluated by Chi-square test.

CRC. Expectedly, due to the decreased secretion of VEGF by CRC cells, the migration and sprouting of HMVECs were impaired in vitro, and neo-vessel formation decreased in vivo. Therefore, these findings suggest that miR-126 is involved in metastatic processes.

DNA methylation and associated silencing of tumorsuppressor genes is a molecular hallmark of human tumors (36). Recently, this phenomenon has been extended to miRNAs with tumor-suppressor features, which are downregulated in multiple tumors (37-39). Saito and Jones (40) reported that DNA methylation induced downregulation of EGFL7, and that demethylation treatment with 5-aza-CdR simultaneously resulted in restoration of miR-126 and its host gene, EGFL7, since as an intronic miRNA, miR-126 tends to co-express with EGFL7. In the present study, we observed extensive promoter methylation in 52 out of 62 primary CRC tissues and 6 cell lines. In addition, 5-aza-CdR treatment of the CRC cell lines restored miR-126 expression and thereby led to a decrease 
in VEGF expression. Our results suggest that silencing of miR-126 by promoter methylation is an important mechanism underlying dysregulation of VEGF expression in CRC.

Tumor metastasis is defined as a consecutive process including local invasion, intravasation, cell survival in the circulatory system, extravasation, and colonization in a secondary site (41). Additionally, angiogenesis is also essential for tumor metastasis. Hurst et al (42) recently proposed a novel category of cancer-related miRNAs termed metastamiRs that are associated with metastatic processes. For instance, miR-21 is a mastermind of metastasis and promotes cell survival, migration, invasion, intravasation and metastasis $(43,44)$, whereas the miR-200 family is delinquent and its absence contributes to the EMT phenotype (45). These metastamiRs are potential cancer prognostic markers and therapeutic targets for metastatic cancers. Our findings provide evidence for the role of miR-126 as a metastamiR through targeting VEGF.

In conclusion, we revealed the inhibitory effects of miR-126 on VEGF, and partly elucidated the potential mechanism by which miR-126 is implicated in CRC metastasis. miR-126 may be a potential target for the therapeutic strategy against CRC.

\section{Acknowledgements}

This study was supported by grants from the National Natural Science Foundation of China (30971520) and the Science and Technology Planning Project of Guangdong Province (2010B031600098).

\section{References}

1. Jemal A, Siegel R, Xu J and Ward E: Cancer statistics, 2010. CA Cancer J Clin 60: 277-300, 2010.

2. Steeg PS: Metastasis suppressors alter the signal transduction of cancer cells. Nat Rev Cancer 3: 55-63, 2003.

3. Winter J, Jung S, Keller S, Gregory RI and Diederichs S: Many roads to maturity: microRNA biogenesis pathways and their regulation. Nat Cell Biol 11: 228-234, 2009.

4. Esquela-Kerscher A and Slack FJ: Oncomirs - microRNAs with a role in cancer. Nat Rev Cancer 6: 259-269, 2006.

5. Place RF, Li LC, Pookot D, Noonan EJ and Dahiya R: MicroRNA373 induces expression of genes with complementary promoter sequences. Proc Natl Acad Sci USA 105: 1608-1613, 2008.

6. Lim LP, Lau NC, Garrett-Engele P, Grimson A, Schelter JM, Castle J, Bartel DP, Linsley PS and Johnson JM: Microarray analysis shows that some microRNAs downregulate large numbers of target mRNAs. Nature 433: 769-773, 2005.

7. Dalmay T and Edwards DR: MicroRNAs and the hallmarks of cancer. Oncogene 25: 6170-6175, 2006.

8. Fish JE, Santoro MM, Morton SU, Yu S, Yeh RF, Wythe JD, Ivey KN, Bruneau BG, Stainier DY and Srivastava D: miR-126 regulates angiogenic signaling and vascular integrity. Dev Cell 15: 272-284, 2008.

9. Wang S, Aurora AB, Johnson BA, Qi X, McAnally J, Hill JA, Richardson JA, Bassel-Duby R and Olson EN: The endothelialspecific microRNA miR-126 governs vascular integrity and angiogenesis. Dev Cell 15: 261-271, 2008.

10. Tavazoie SF, Alarcón C, Oskarsson T, Padua D, Wang Q, Bos PD, Gerald WL and Massagué J: Endogenous human microRNAs that suppress breast cancer metastasis. Nature 451: 147-152, 2008.

11. Hamada S, Satoh K, Fujibuchi W, Hirota M, Kanno A, Unno J, Masamune A, Kikuta K, Kume K and Shimosegawa T: MiR-126 acts as a tumor suppressor in pancreatic cancer cells via the regulation of ADAM9. Mol Cancer Res 10: 3-10, 2012.

12. Feng R, Chen X, Yu Y, Su L, Yu B, Li J, Cai Q, Yan M, Liu B and Zhu Z: miR-126 functions as a tumour suppressor in human gastric cancer. Cancer Lett 298: 50-63, 2010.

13. Donnem T, Fenton CG, Lonvik K, Berg T, Eklo K, Andersen S, Stenvold H, Al-Shibli K, Al-Saad S, Bremnes RM and Busund LT: MicroRNA signatures in tumor tissue related to angiogenesis in non-small cell lung cancer. PLoS One 7: e29671, 2012.
14. Jiao LR, Frampton AE, Jacob J, Pellegrino L, Krell J, Giamas G, Tsim N, Vlavianos P, Cohen P, Ahmad R, Keller A, Habib NA, Stebbing $\mathrm{J}$ and Castellano L: MicroRNAs targeting oncogenes are down-regulated in pancreatic malignant transformation from benign tumors. PLoS One 7: e32068, 2012.

15. Miko E, Margitai Z, Czimmerer Z, Várkonyi I, Dezso B, Lányi A, Bacsó Z and Scholtz B: miR-126 inhibits proliferation of small cell lung cancer cells by targeting SLC7A5. FEBS Lett 585: 1191-1196, 2011.

16. Crawford M, Brawner E, Batte K, Yu L, Hunter MG, Otterson GA, Nuovo G, Marsh CB and Nana-Sinkam SP: MicroRNA-126 inhibits invasion in non-small cell lung carcinoma cell lines. Biochem Biophys Res Commun 373: 607-612, 2008.

17. Otsubo T, Akiyama Y, Hashimoto Y, Shimada S, Goto K and Yuasa Y: MicroRNA-126 inhibits SOX2 expression and contributes to gastric carcinogenesis. PLoS One 6: e16617, 2011.

18. Watahiki A, Wang Y, Morris J, Dennis K, O'Dwyer HM, Gleave M, Gout PW and Wang Y: MicroRNAs associated with metastatic prostate cancer. PLoS One 6: e24950, 2011.

19. Ferrara N and Kerbel RS: Angiogenesis as a therapeutic target. Nature 438: 967-974, 2005.

20. Grothey A and Galanis E: Targeting angiogenesis: progress with anti-VEGF treatment with large molecules. Nat Rev Clin Oncol 6: 507-518, 2009.

21. Li XM, Wang AM, Zhang J and Yi H: Down-regulation of miR-126 expression in colorectal cancer and its clinical significance. Med Oncol 28: 1054-1057, 2011.

22. Saito Y, Friedman JM, Chihara Y, Egger G, Chuang JC and Liang G: Epigenetic therapy upregulates the tumor suppressor microRNA-126 and its host gene EGFL7 in human cancer cells. Biochem Biophys Res Commun 379: 726-731, 2009.

23. Watanabe K, Emoto N, Hamano E, Sunohara M, Kawakami M, Kage H, Kitano K, Nakajima J, Goto A, Fukayama M, Nagase T, Yatomi Y, Ohishi N and Takai D: Genome structure-based screening identified epigenetically silenced microRNA associated with invasiveness in non-small-cell lung cancer. Int $\mathbf{J}$ Cancer 130: 2580-2590, 2012.

24. Roccaro AM, Hideshima T, Raje N, Kumar S, Ishitsuka K, Yasui H, Shiraish N, Ribatti D, Nico B, Vacca A, Dammacco F, Richardson PG and Anderson KC: Bortezomib mediates antiangiogenesis in multiple myeloma via direct and indirect effects on endothelial cells. Cancer Res 66: 184-191, 2006.

25. Kloosterman WP and Plasterk RH: The diverse functions of microRNAs in animal development and disease. Dev Cell 11: 441-450, 2006.

26. Weis SM and Cheresh DA: Tumor angiogenesis: molecular pathways and therapeutic targets. Nat Med 17: 1359-1370, 2011.

27. Gaziel-Sovran A, Segura MF, Di Micco R, Collins MK, Hanniford D, Vega-Saenz de Miera E, Rakus JF, Dankert JF, Shang S, Kerbel RS, Bhardwaj N, Shao Y, Darvishian F, Zavadil J, Erlebacher A, Mahal LK, Osman I and Hernando E: $M i R-30 b / 30 d$ regulation of GalNAc transferases enhances invasion and immunosuppression during metastasis. Cancer Cell 20: 104-118, 2011

28. Yang $\mathrm{CH}$, Yue J, Pfeffer SR, Handorf CR and Pfeffer LM: MicroRNA-21 regulates the metastatic behavior of B16 melanoma cells. J Biol Chem 286: 39172-39178, 2011.

29. Fang JH, Zhou HC, Zeng C, Yang J, Liu Y, Huang X, Zhang JP, Guan XY and Zhuang SM: MicroRNA-29b suppresses tumor angiogenesis, invasion, and metastasis by regulating matrix metalloproteinase 2 expression. Hepatology 54: 1729-1740, 2011.

30. Xu Y, Zhao F, Wang Z, Song Y, Luo Y, Zhang X, Jiang L, Sun Z, Miao Z and Xu H: MicroRNA-335 acts as a metastasis suppressor in gastric cancer by targeting Bcl-w and specificity protein 1. Oncogene 31: 1398-1407, 2012.

31. Wang S and Olson EN: AngiomiRs - key regulators of angiogenesis. Curr Opin Genet Dev 19: 205-211, 2009.

32. Png KJ, Halberg N, Yoshida M and Tavazoie SF: A microRNA regulon that mediates endothelial recruitment and metastasis by cancer cells. Nature 481: 190-194, 2011.

33. Zhu X, Li H, Long L, Hui L, Chen H, Wang X, Shen $\mathrm{H}$ and Xu W: miR-126 enhances the sensitivity of non-small cell lung cancer cells to anticancer agents by targeting vascular endothelial growth factor A. Acta Biochim Biophys Sin 44: 519-526, 2012.

34. Stoeltzing O, Liu W, Reinmuth N, Parikh A, Ahmad SA, Jung YD, Fan F and Ellis LM: Angiogenesis and antiangiogenic therapy of colon cancer liver metastasis. Ann Surg Oncol 10: 722-733, 2003.

35. Fan F, Wey JS, McCarty MF, Belcheva A, Liu WB, Bauer TW, Somcio RJ, Wu Y, Hooper A, Hicklin DJ and Ellis LM: Expression and function of vascular endothelial growth factor receptor-1 on human colorectal cancer cells. Oncogene 24: 2647-2653, 2005. 
36. Esteller M: Epigenetics in cancer. N Engl J Med 358: 1148-1159, 2008.

37. Lujambio A, Calin GA, Villanueva A, Ropero S, SánchezCéspedes M, Blanco D, Montuenga LM, Rossi S, Nicoloso MS, Faller WJ, Gallagher WM, Eccles SA, Croce CM and Esteller M: A microRNA DNA methylation signature for human cancer metastasis. Proc Natl Acad Sci USA 105: 13556-13561, 2008.

38. Toyota M, Suzuki H, Sasaki Y, Maruyama R, Imai K, Shinomura Y and Tokino T: Epigenetic silencing of microRNA-34b/c and B-cell translocation gene 4 is associated with $\mathrm{CpG}$ island methylation in colorectal cancer. Cancer Res 68: 4123-4132, 2008.

39. Huang YW, Liu JC, Deatherage DE, Luo J, Mutch DG, Goodfellow PJ, Miller DS and Huang TH: Epigenetic repression of microRNA-129-2 leads to overexpression of SOX4 oncogene in endometrial cancer. Cancer Res 69: 9038-9046, 2009.

40. Saito Y and Jones PA: Epigenetic activation of tumor suppressor microRNAs in human cancer cells. Cell Cycle 5: 2220-2222, 2006.

41. Nguyen DX, Bos PD and Massagué J: Metastasis: from dissemination to organ-specific colonization. Nat Rev Cancer 9: 274-284, 2009.
42. Hurst DR, Edmonds MD and Welch DR: Metastamir: the field of metastasis-regulatory microRNA is spreading. Cancer Res 69: 7495-7498, 2009.

43. Wang P, Zou F, Zhang X, Li H, Dulak A, Tomko RJ Jr, Lazo JS, Wang Z, Zhang L and Yu J: microRNA-21 negatively regulates Cdc25A and cell cycle progression in colon cancer cells. Cancer Res 69: 8157-8165, 2009.

44. Asangani IA, Rasheed SA, Nikolova SA, Leupold JH, Colburn NH, Post S and Allgayer H: MicroRNA-21 (miR-21) post-transcriptionally downregulates tumor suppressor Pdcd4 and stimulates invasion, intravasation and metastasis in colorectal cancer. Oncogene 27: 2128-2136, 2008.

45. Gregory PA, Bert AG, Paterson EL, Barry SC, Tsykin A, Farshid G, Vadas MA, Khew-Goodall Y and Goodall GJ: The miR-200 family and miR-205 regulate epithelial to mesenchymal transition by targeting ZEB1 and SIP1. Nat Cell Biol 10: 593-601, 2008. 